\title{
Hnalysis of Hematological and Biochemical Parameters in Methamphetamine Hddicts Compared with Healthy Individuals
}

Fataneh Tavasolian (MSc)

Department of Immunology, Faculty of Medicine, Tarbiat modares University of Medical Sciences, Tehran, Iran

Elham Abdollahi (MSc)

Department of Immunology, Faculty of

Medicine, Mashhad University of Medical

Sciences, Mashhad, Iran

Morteza Samadi (PhD)

Department of Immunology, Faculty of Medicine, Shahid Sadoughi University of Medical Sciences, Yazd, Iran

Mahmood Vakili (PhD)

Department of Community Medicine, Faculty of Medicine, Shahid Sadoughi University of Medical Sciences, Yazd, Iran corresponding author: Morteza Samadi

Email:samadifor@gmail.com

Tel:+989122601505

Address: University of Medical Sciences, Yazd, Iran

Received: 19 Oct 2014

Revised: 08 Dec 2014

Accepted: 16 Dec 2014

\section{ABSTRACT}

Background and Objective: Methamphetamine has strong stimulating effects on various systems of the human body. The aim of this study was to evaluate the hematological and biochemical parameters in methamphetamine addicts and to compare them with healthyindividuals.

Methods: This is a retrospective case-control study that was conducted in 1390-91 in Ibn Sina Hospital in Shiraz, Iran. Measurement of lipids (cholesterol, triglycerides), liver enzymes (alanine aminotransferase, aspartate aminotransferase, alkaline phosphatase), albumin, blood urea nitrogen, creatinine and blood parameters such as platelets and white blood cells(WBCs) count, hemoglobin concentration and hematocrit of 60 individuals addicted to methamphetamine and 60 healthy subjects as a control group was carried out.

Results: Alanine aminotransferase, aspartate amino transferase, alkaline phosphatase, WBCs and platelet count and serum creatinine levels in methamphetamine addicts were significantly higher than the control group(p-value $<0.001)$, while hemoglobin, hematocrit and albumin levels were lower in these patients (p-value $<0.001$ ).

Conclusion: The use of methamphetamine increases lipid peroxidation, changes levels of inflammatory markers and increases liver enzymes, which may increase the risk of liver diseases. It also increases WBC's and platelets count as an early sign of inflammatory disease progression, associated with methamphetamine abuse. Decreased hemoglobin and hematocrit can also increase the risk of anemia in these patients. These observations may give us a better understanding about the biological mechanisms associated with the pathology of methamphetamine consumption in Iran and help us prevent and solve the problems arising from this drug.

Keywords: Methamphetamine, Hematological Tests, Biological Markers, 0xidative Stress. 


\section{INTRODUCTION}

The number of methamphetamine (MA) addicts in Iran is rising, a condition which can lead to serious health and social problems. It can also increase the risk of various diseases including acute kidney problems, cardiovascular and neurological diseases in older individuals (1-3). Methamphetamine has strong stimulating effects on the central nervous system (CNS), increases euphoria and consciousness and decreases appetite (4). Methamphetamine's mechanism of effect is mainly through dopamine and serotonin release in the CNS (5). Animal studies have shown that methamphetamine increases inflammation and oxidative stress (5), which in turn may cause respiratory, cardiovascular and neurological disorders (6). Oxidative stress is defined as the imbalance between oxidants and antioxidants in biological systems. Macromolecules are damaged by free radicals when this imbalance occurs $(7,8)$. A study on the oxidative effects of methamphetamine on dopamine in rats has shown that the production of reactive oxygen intermediates in synaptosomes increases, while Methamphetamine is unable to induce the production of reactive oxygen intermediates in animals lacking dopamine synaptosomes(9). Since our knowledge about the biochemical mechanisms and pathological conditions related to methamphetamine addiction is insufficient, this study was aimed to examine the hematological and biochemical parameters in methamphetamine addicts compared to healthy subjects.

\section{MATERIAL AND METHODS}

Subjects: Study population consisted 120 adult males, 60 of whom had a history of methamphetamine use and 60 healthy subjects with no history of drug abuse. All the subjects underwent physical examination and medical history was obtained to identify healthy individuals from addicts. Individuals who were classified in the group of methamphetamine consumers had the following criteria: Age between 20-50. Use of methamphetamine on a regular basis for at least 3 months and at least 5 days a week Exclusion criteria included: HIV infection, History of drug dependence (other than methamphetamine, nicotine, caffeine)
History of any chronic disease, nervous and mental illness (e.g. Convulsion, depression, high blood pressure, heart disease, diabetes or liver disease). Sera was used to determine the biochemical variables such as albumin, blood urea nitrogen (BUN), creatinine, total cholesterol, triglycerides, aspartate aminotransferase (AST), alanine aminotransferase (ALT), alkaline phosphatase (ALP) and uric acid. Blood containing anticoagulant EDTA was used to determine hemoglobin, hematocrit, platelets and white blood cells (WBC) count. This experimental study was approved by the research ethics committee. Laboratory Techniques: Blood samples were collected after 12 hours fasting. Total cholesterol, triglycerides, BUN, creatinine, uric acid, AST, ALT and ALP were measured by enzymatic methods using commercial kits (MAN Co.). WBC hemoglobin, hematocrit, platelets weew measured by Sysmex Kx 21 cell counter. Statistical analysis: Statistical analysis was performed using SPSS version 16 statistical software. Mean and confidence intervals (CI) of 95\% were measured in groups. The difference between the means was analyzed using the Student's t-Tests and P-value of $<0.05$ was considered as statistical significance.

\section{RESULTS}

The mean duration of methamphetamine abuse among the test groups was about 3 years. The mean and confidence intervals $(\mathrm{CI}=95 \%)$ for biochemical and blood parameters in addicts and controls are shown in Table 1. There was no significant difference in the amount of BUN, fat and uric acid between the two test groups. The number of platelets and WBC among methamphetamine consumers was notably higher than the controls (P-value <0.001). However, albumin, hemoglobin and hematocrit in the methamphetamine group were significantly lower than the control group (Pvalue $<0.001$ ). Increased levels of creatinine and liver enzymes such as AST, ALT and ALP was observed among drug abusers compared to the healthy subjects ( $\mathrm{P}$ value $<0.001)$. 
Table 1- Mean and 95\% confidence intervals for hematological and biochemical parameters in methamphetamine consumers and healthy subjects

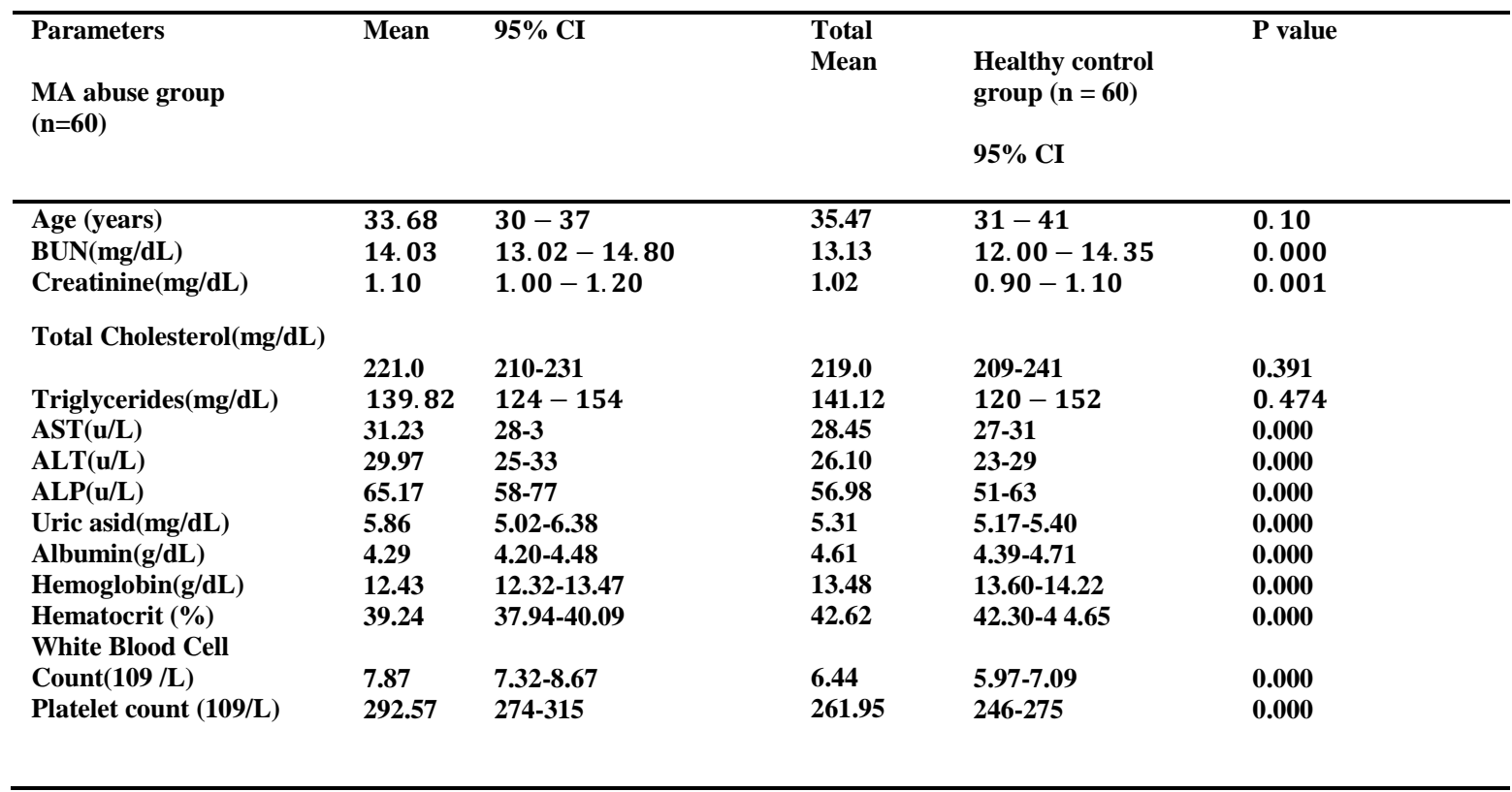

\section{DISCUSSION}

Methamphetamine release in Presynaptic nerve terminals of neurotransmitters such as norepinephrine, dopamine and catecholamine leads to poisoning, stimulates post-synaptic receptors and inhibits reuptake of the neurotransmitters $(10,11)$. High levels of these neurotransmitters by auto-oxidation mechanism or destruction of monoamine oxygenase are responsible for the production of reactive oxygen species (ROS) and oxidative stress (5, 12, 13). Animal studies have well-established the effects of methamphetamine in the production of ROS $(11,14)$. ROS can response to macromolecules such as proteins, lipids and DNA which result in cellular dysfunction (9, 15), reaction of ROS with lipids and consequently lipid peroxidation. Many studies have shown that methamphetamine can activate transcription factors that play an important role in the signaling pathway, inflammatory gene regulation such as tumor necrosis factor (TNF- $\alpha$ ) (16). Oxidative stress can cause damage to many biological molecules in the body and is a factor involved in the pathogenesis of inflammatory diseases $(17,18)$. It has been demonstrated that increased inflammatory reactions after methamphetamine consumption increases microglial activity and results in secretion of pro-inflammatory cytokine, prostaglandin, nitric oxide and superoxide, all of which damage the nervous tissue. Moreover, microglia can cause inflammation by increasing the secretion of inflammatory cytokines such as IL-1 $\beta$, IL-6 and $\mathrm{TNF} \alpha(5,19)$. The results of a recent study has shown that methamphetamine can significantly change inflammatory markers such as the number of WBCs, platelets and albumin levels compared to healthy controls and increases the risk of inflammatory diseases. Another study on animals showed that methamphetamine can change biochemical variables including creatinine and albumin levels and blood cell count (20). The number of WBCs may indicate the exposure to oxidative and inflammatory response and host susceptibility to inflammatory stimuli (21).It was also demonstrated that methamphetamine increases oxidative damageand impairs the function of T-cells (22). Platelets represent an important link between inflammation and thrombosis due to their ability to interact with WBC and endothelial cells. They can also release factors that are involved in inflammation and coagulation (23). Albumin is one of the acute phase proteins with antioxidant properties that can be used as an indicator of inflammation $(24,25)$. As mentioned previously, the use of methamphetamine causes inflammation and oxidative stress, thus it may affect inflammatory markers such as the number of WBCs, platelets and albumin levels. 
However, the mechanisms by which methamphetamine can induce inflammation is not clearly understood. Yamaguchi and his colleagues have shown that methamphetamine increases the level of pro inflammatory cytokines such as IL-1 $(26,27)$. Flora et al. have represented that methamphetamine can activate activator protein-1 (AP-1) which plays a role in the signaling pathways, resulting in inflammatory gene regulation within the body (6). Thus, this study shows the association of Methamphetamine use with increased oxidative stress, inflammatory markers and increased adverse effects on health. Methamphetamine is metabolized in the liver microsomes by cytochrome P450s with half-life of about 10-12 hours $(28,29)$. Liver injury can be another effect of methamphetamine use and a range of clinical protests from acute and chronic hepatitis have been demonstrated in previous studies $(30,31)$. Possible mechanisms of liver damage by methamphetamine includes; lipid peroxidation and toxic effects on liver cells (32). A recent study showed that methamphetamine use increases the level of liver enzymes and increases the risk of liver diseases. Methamphetamine is a stimulant with large side effects on appetite which can lead to weight loss and malnutrition (33). It was also demonstrated

\section{REFERENCES}

1. $\mathrm{Yu} \mathrm{Q}$, Larson DF, Watson RR. Heart disease, methamphetamine and AIDS. Life sciences. 2003; 73(2): 129-40.

2. Terada Y, Shinohara S, Matui N, Ida T. Amphetamineinduced myoglobinuric acute renal failure. Japanese journal of medicine. 1988; 27(3): 305-8.

3. Chang L, Ernst T, Speck O, Patel H, DeSilva M, Leonido-Yee M, et al. Perfusion MRI and computerized cognitive test abnormalities in abstinent methamphetamine users. Psychiatry Research: Neuroimaging. 2002; 114(2): 65-79.

4. Thrash B, Karuppagounder SS, Uthayathas S, Suppiramaniam V, Dhanasekaran M. Neurotoxic effects of methamphetamine. Neurochemical research. 2010;35(1):171-9. doi: 10.1007/s11064-009-0042-5.

5. Yamamoto BK, Raudensky J. The role of oxidative stress, metabolic compromise, and inflammation in neuronal injury produced by amphetamine-related drugs of abuse. Journal of Neuroimmune Pharmacology. 2008; 3(4): 203-17.

6. Flora G, Lee YW, Nath A, Hennig B, Maragos W, Toborek M. Methamphetamine potentiates HIV-1 Tat protein-mediated activation of redox-sensitive pathways in discrete regions of the brain. Experimental neurology. 2003; 179(1): 60- that methamphetamine consumers have reduced hemoglobin and hematocrit concentrations compared to healthy individuals, which increases the risk of anemia in this population (34). Thus, it can be concluded that methamphetamine consumption can affect public health both directly and indirectly.

\section{CONCLUSION}

Methamphetamine addicts have increased levels of inflammatory markers, elevated liver enzymes and increased number of WBCs and platelets, which may increase the risk of acute and chronic liver diseases. Reduction in hemoglobin and hematocrit concentrations will also increase the risk of anemia. These observations may give us a better approach to pathobiological mechanisms associated with methamphetamine use and help us solve the problems arising from the use of this drug. ACKNOWLEDGMENT

I would like to thank all the colleagues who worked with us in this study, especially the management and staff of Ibn Sina Hospital.

\section{CONFLICT OF INTEREST}

The authors declare no conflict of interest between them.

7. Goodyear-Bruch C, Pierce JD. Oxidative stress in critically ill patients. American Journal of Critical Care. 2002; 11(6): 543-51.

8. Romero FJ, Bosch-Morell F, Romero MJ, Jareño EJ, Romero B ,Marín N, et al. Lipid peroxidation products and antioxidants in human disease. Environmental Health Perspectives. 1998; 106(Suppl 5): 1229-34.

9. Pubill D, Chipana C, Camins A, Pallàs M, Camarasa J, Escubedo E. Free radical production induced by methamphetamine in rat striatal synaptosomes. Toxicology and applied pharmacology. 2005; 204(1): 57-68.

10. Waksman J, Taylor Jr RN, Bodor GS, Daly FF, Jolliff HA, Dart RC, editors. Acute myocardial infarction associated with amphetamine use. Mayo Clinic Proceedings. 2001; 76(3): 323-6.

11. Yamamoto $\mathrm{BK}$, Zhu W. The effects of methamphetamine on the production of free radicals and oxidative stress. Journal of Pharmacology and Experimental Therapeutics. 1998; 287(1): 107-14.

12. Fumagalli F, Gainetdinov RR, Valenzano KJ, Caron MG. Role of dopamine transporter in methamphetamineinduced neurotoxicity: evidence from mice lacking the transporter. The Journal of neuroscience. 1996;18(13):4861-9. 
13. Filloux F, Townsend JJ. Pre-and postsynaptic neurotoxic effects of dopamine demonstrated by intrastriatal injection. Experimental neurology. 1993; 119(1): 79-88. PMID: 8432353.

14. Hartz DT, Frederick-Osborne SL, Galloway GP. Craving predicts use during treatment for methamphetamine dependence: a prospective, repeatedmeasures, within-subject analysis. Drug and alcohol dependence. 2001; 63(3): 269-76. PMID:11418231.

15. Wu C-W, Ping Y-H, Yen J-C, Chang C-Y, Wang S-F, Yeh C-L, et al. Enhanced oxidative stress and aberrant mitochondrial biogenesis in human neuroblastoma $\mathrm{SH}$ SY5Y cells during methamphetamine induced apoptosis . Toxicology and applied pharmacology. 2007; 220(3): 24351.

16. Park M, Hennig B, Toborek M. Methamphetamine alters occludin expression via NADPH oxidase-induced oxidative insult and intact caveolae. Journal of Cellular and Molecular Medicine. 2012; 16(2): 362-75. doi: 10.1111/j.1582-4934.2011.01320.x.

17. Galasko D, Montine TJ. Biomarkers of oxidative damage and inflammation in Alzheimer's disease. Biomarkers. 2010; 4(1): 27-36.

18. Lakshmi S, Padmaja G, Kuppusamy P, Kutala VK. Oxidative stress in cardiovascular disease. Indian $\mathrm{J}$ Biochem Biophys. 2009; 46(6): 421-40.

19. Melo P, Zanon-Moreno V, Alves CJ, Magalhães A, Tavares MA, Pinazo-Duran MD, et al. Oxidative stress response in the adult rat retina and plasma after repeated administration of methamphetamine. Neurochemistry international. 2010; 56(3): 431-6 doi: 10.1016/j.neuint.2009.11.017.

20. Saito M, Yamaguchi T, Kawata T, Ito H, Kanai T, Terada M, et al. Effects of methamphetamine on cortisone concentration, $N K$ cell activity and mitogen response of $T$ lymphocytes in female cynomolgus monkeys. Experimental animals. 2006; 55(5): 477-81.

21. Crowell RJ, Samet JM. Invited Commentary: Why Does the White Blood Cell Count Predict Mortality? American Journal of Epidemiology. 1995; 142(5): 499-501.

22. Potula R, Hawkins BJ, Cenna JM, Fan S, Dykstra H, Ramirez SH, et al. Methamphetamine causes mitrochondrial oxidative damage in human T lymphocytes leading to functional impairment. The Journal of Immunology. 2010; 185(5): 2867-76. doi: 10.4049/jimmunol.0903691.

23. Sarma J, Laan CA, Alam S, Jha A, Fox KA, Dransfield I. Increased platelet binding to circulating monocytes in acute coronary syndromes. Circulation. 2002 May $7 ; 105(18): 2166-71$
24. Himmelfarb J, McMonagle E. Albumin is the major plasma protein target of oxidant stress in uremia. Kidney international. 2001;60(1):358-63. PMID:11422772.

25. Wu G. Amino acids: metabolism, functions, and nutrition. Amino acids. 2009; 37(1): 1-17. doi: 10.1007/s00726-009-0269-0.

26. Gonçalves J, Martins T, Ferreira R, Milhazes N, Borges F, Ribeiro CF, et al. Methamphetamine-Induced Early Increase of IL- 6 and TNF- $\alpha$ mRNA Expression in the Mouse Brain. Annals of the New York Academy of Sciences. 2008;1139(1):103-11. doi: 10.1196/annals.1432.043.

27. Yamaguchi T, Kuraishi Y, Minami M, Nakai S, Hirai Y, Satoh M. Methamphetamine-induced expression of interleukin-1 $\beta$ mRNA in the rat hypothalamus. Neuroscience letters. 1991; 128(1): 90-2. PMID:1922954.

28. Dostálek M, Jurica J, Pistovcakova J, Hanesová M, Tomandl J, Linhart I, et al. Effect of methamphetamine on cytochrome P450 activity. Xenobiotica. 2007;37(12):135566 PMID: 17922362

29. Schepers RJ, Oyler JM, Joseph RE, Cone EJ, Moolchan ET, Huestis MA. Methamphetamine and amphetamine pharmacokinetics in oral fluid and plasma after controlled oral methamphetamine administration to human volunteers. Clinical Chemistry. 2003;49(1):121-32. PMID:12507968.

30. Kamijo Y, Soma K, Nishida M, Namera A, Ohwada T. Acute liver failure following intravenous methamphetamine. Veterinary and human toxicology. 2002; 44(4): 216-7 PMID:12136967.

31. Dahshan A. Prenatal exposure to methamphetamine presenting as neonatal cholestasis. Journal of clinical gastroenterology. 2009; 43(1): 88-90. doi: 10.1097/MCG.0b013e31812f4fof.

32. Shannon B, Borron SW, Snook CP, Handel DA, Arias JC, Osterloh JD, et al. Haddad and Winchester's clinical management of poisoning and drug overdose. System; 2006; 133:1

33. Werb D, Kerr T, Zhang R, Montaner JS, Wood E. Methamphetamine use and malnutrition among streetinvolved youth. Harm reduction journal. 2010; 7: 5. doi:10.1186/1477-7517-7-5.

34. Jackson RT, Al-Mousa Z. Iron deficiency is a more important cause of anemia than hemoglobinopathies in Kuti adolescent girls. The Journal of nutrition. 2000; 130(5): 1212-6 